\title{
Pain prevalence in a pediatric hospital: Raising awareness during Pain Awareness Week
}

\author{
Denise Harrison RN PhD ${ }^{1,2,3,4}$, Cynthia Joly RN MScN ${ }^{1}$, Christine Chretien RN BScN ${ }^{1}$, \\ Sarah Cochrane RN BSCN${ }^{1}$, Jacqueline Ellis RN PhD ${ }^{1,3}$, Christine Lamontagne MDCM FRCPC ${ }^{1}$, \\ Regis Vaillancourt OMM CD BPharm Pharm D FCSHP ${ }^{1}$
}

D Harrison, C Joly, C Chretien, et al. Pain prevalence in a pediatric hospital: Raising awareness during Pain Awareness Week. Pain Res Manag 2014;19(1):e24-e30.

BACKGROUND: Despite the evidence and availability of numerous validated pain assessment tools and pain management strategies for infants and children, their use remains inconsistent in clinical practice.

OBJECTIVES: To describe the prevalence of pain, pain assessment and pain management practices at a tertiary pediatric hospital in Canada.

METHODS: The cross-sectional study design involved a combination of interviews with children and/or caregivers, and chart audits in five inpatient units. Information regarding pain intensity, painful procedures and pain management strategies was obtained from children and/or caregivers by interview. Patient charts were reviewed for information regarding pain assessment, pain scores, and pharmacological and nonpharmacological interventions.

RESULTS: Sixty-two children (four days to 17 years of age) participated. Most children or their caregivers $(n=51[84 \%])$ reported that pain was experienced during their hospitalization, with 40 (66\%) reporting their worst pain as moderate or severe. Almost one-half reported analgesics were administered before or during their most recent painful procedure. Nineteen $(32 \%)$ reported sucrose, topical anesthetics or nonpharmacological interventions were used; however, they were documented in only $17 \%$ of charts. Pain scores were documented in $34(55 \%)$ charts in the previous $24 \mathrm{~h}$. The majority of the children or their caregiver ( $n=44$ [71\%]) were satisfied with pain management at the study hospital.

CONCLUSIONS: Most infants and children had experienced moderate or severe pain during their hospitalization. Analgesics were frequently used, and although nonpharmacological strategies were reported to be used, they were rarely documented. Most parents and children were satisfied with their pain management.

Key Words: Children; Infants; Pain; Pain assessment; Pain management

\section{La prévalence de la douleur dans un hôpital pédiatrique : la faire connaître pendant la Semaine nationale de sensibilisation au problème de la douleur}

HISTORIQUE : Malgré les données probantes et l'existence de nombreux outils validés d'évaluation de la douleur et de nombreuses stratégies de gestion de la douleur pour les nourrissons et les enfants, leur utilisation demeure irrégulière en pratique clinique.

OBJECTIFS : Décrire la prévalence de la douleur, l'évaluation de la douleur et les pratiques de gestion de la douleur dans un hôpital pédiatrique de soins tertiaires du Canada.

MÉTHODOLOGIE : L'étude transversale se composait d'une combinaison d'entrevues avec des enfants ou les personnes qui s'occupaient d'eux et de vérification des dossiers dans cinq unités de patients hospitalisés. Les chercheurs ont obtenu l'information relative à l'intensité de la douleur, aux interventions douloureuses et aux stratégies de gestion de la douleur auprès des enfants ou des personnes qui s'occupaient d'eux, dans le cadre d'une entrevue. Ils ont examiné les dossiers des patients pour obtenir de l'information au sujet de l'évaluation de la douleur, de l'indice de douleur et des interventions pharmacologiques et non pharmacologiques.

RÉSULTATS : Soixante-deux enfants (de quatre jours à 17 ans) ont participé à l'étude. La plupart des enfants ou des personnes qui s'occupaient d'eux ( $\mathrm{n}=51 ; 84 \%$ ) ont affirmé que de la douleur avait été ressentie pendant l'hospitalisation, 40 (66 \%) précisant que leur douleur la plus intense était modérée ou violente. Près de la moitié ont indiqué que des analgésiques avaient été administrés avant ou pendant l'intervention douloureuse la plus récente. Dix-neuf (32\%) ont déclaré que du sucrose, des anesthésiques topiques ou des interventions non pharmacologiques avaient été utilisés, mais ceux-ci ne figuraient que dans $17 \%$ des dossiers. Les indices de douleur étaient consignés dans 34 dossiers (55\%) au cours des 24 heures précédentes. La majorité des enfants ou des personnes qui s'occupaient d'eux ( $\mathrm{n}=44 ; 71 \%$ ) étaient satisfaits de la gestion de la douleur utilisée à l'hôpital de l'étude.

CONCLUSIONS : La plupart des nourrissons et des enfants ont ressenti une douleur modérée à violente pendant leur hospitalisation. Les analgésiques étaient souvent utilisés, et même si des stratégies non pharmacologiques avaient été utilisées, elles étaient rarement inscrites au dossier. La plupart des parents et des enfants étaient satisfaits de la gestion de la douleur qui leur avait été offerte.

Ontario) in 2008 indicated that $23 \%$ of the 290 children surveyed had moderate or severe pain on the day of their study interview and $64 \%$ had moderate or severe pain in the previous $24 \mathrm{~h}$ (4). Similarly, a study conducted over five consecutive hospital days in a pediatric oncology ward in a hospital in the USA showed that approximately one-half of the 49 children had experienced pain and 33\% of those patients had experienced moderate or severe pain (5).

The consequences of unmanaged pain in infants and children are both immediate and long term. Painful procedures performed in infancy such as heel lancing or circumcision correlate with stronger negative responses to venipuncture and intramuscular vaccinations weeks to months later (6-9), and Rennick et al (10) reported that the number of painful procedures was the strongest predictor of poorer lence survey undertaken at The Hospital for Sick Children (Toronto,

${ }^{1}$ Children's Hospital of Eastern Ontario, Ottawa, Ontario; ${ }^{2}$ University of Melbourne, Victoria, Australia; ${ }^{3}$ University of Ottawa, Faculty of

Health Sciences, Ottawa, Ontario; ${ }^{4}$ Murdoch Children's Research Institute, Parkville, Victoria, Australia

Correspondence: Dr Denise Harrison, Children's Hospital of Eastern Ontario, 401 Smyth Road, CPCR L1158, Ottawa, Ontario K1H 8L1.

Telephone 613-737-7600, ext 4140, fax 613-737-6504, e-mail dharrison@cheo.on.ca 
TABLE 1

Interview tool

Question
Worst pain during hospitalization
Current pain score at rest
Current pain score with movement
Pain score obtained by
During your last needle stick (or poke) what sort of things did the nurse/doctors/blood
collectors/child life specialists do to help you/your child

Most recent painful procedure/episode

Were pain medications given prior to the procedure or early in the episode Were non-pharmacological strategies used during/prior to the procedure or early in the episode Overall satisfaction with pain management

Range of possible responses
Four-point numerical rating scale*
Four-point numerical rating scale*
Four-point numerical rating scale*
Child, parents/guardian, nurse
Sucrose, swaddling, blowing bubbles, encourage breastfeeding
during procedures, numbing cream (EMLA ${ }^{\dagger}$, Ametop $\left.{ }^{\ddagger}\right)$, Pain
Ease§, guided imagery, encourage kangaroo care during
procedures, distraction (toy, book, etc), breathing exercises,
position for comfort, nothing specific, other
Blood draw, peripheral intravenous needle insertaion, dressing
change, lumbar puncture, headache, joint ache, tummy ache,
incision pain, other
Yes, no, unsure
Yes, no, unsure
Four-point numerical rating scale*

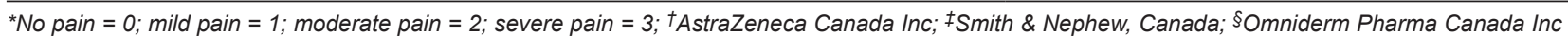

psychological outcomes in hospitalized children. Health professionals have a responsibility to ensure that optimal pain management is provided to hospitalized children.

Studies evaluating treatment for procedural pain in children have increased tremendously over the past decade, resulting in reviews of systematic reviews of pain management interventions for acute procedural pain $(11,12)$. Effective interventions for infants include kangaroo care, facilitated tucking, breastfeeding when feasible, and sucrose with or without non-nutritive sucking (12-15) and, for children, topical anesthetics, distraction and hypnosis (11). Despite well-documented evidence of the benefits of these interventions, their use remains inconsistent in clinical practice (1-3) and hospitalized infants and children continue to experience significant procedural pain.

A previous pain prevalence study at the study hospital published a decade ago (16) indicated that nurses and physicians identified variability in practice as a barrier to good pain management (16). Since that time, an Integrated Pain Service has been developed, comprising nursing, anesthesiology, pharmacy and psychology. In addition, since 1998, there has been an active Pain Resource Nurse (PRN) program in place within the organization. The PRNs act as pain champions and facilitators, are unit-based, and provide education and support to nurses on all inpatient units.

The 2011 National Pain Awareness Week provided an opportunity to examine current pain management throughout the organization to gauge our progress and use the results as a benchmark to compare with other pediatric centers and to ourselves in the future.

The goal of the present study was threefold: to describe the prevalence of pain in hospitalized children at a single point in time during National Pain Awareness Week; to describe pain management practices used at the same single point in time during National Pain Awareness Week; and to provide unit-specific results to participating inpatient units as a quality improvement activity.

\section{Design}

\section{METHODS}

The study design was prospective and cross-sectional. It included faceto-face interviews with children and/or caregivers of infants and children who were unable to self-report, and chart audits.

\section{Setting and sample}

The setting was a tertiary pediatric teaching hospital serving Eastern and parts of Northern Ontario, Western Quebec and Nunavut. It has a catchment area of approximately 600,000 children, $\leq 18$ years of age.
The annual case volume for 2010/2011 was 6529 admissions. The study population included all inpatients in the 165-bed hospital in Eastern Ontario on a single day, with the exception of critically ill unconscious children, children receiving neuromuscular blockers and children nursed in the Mental Health Inpatient Unit. In addition, children whose length of stay in the inpatient unit was $<8 \mathrm{~h}$ were excluded because data would not clearly reflect the care received from that specific unit.

\section{Measures}

The data collection tool developed by the study team consisted of two components: an interview tool (Table 1) and a chart audit tool. The interview tool consisted of seven questions that included asking children, if able, or their caregiver, to rate their current pain intensity at rest and during movement, and their worst pain experienced during the current hospitalization. A four-point scale was used as follows: no pain $=0$; mild pain $=1$; moderate pain $=2$; and severe pain $=3$. This simple four-point scale, based on that used by Taylor et al (4), which has been shown to correlate with other pain measures (17), enabled a single, consistent measure to be used with all participating infants, children and/or parents. If children or caregivers reported a score of 2 or 3 (moderate or severe pain) for current pain either at rest or with movement, the study nurses reported this to the child's nurse to ensure appropriate pain management was instituted. Children and caregivers were also asked what their most recent painful procedure or episode was, and what pharmacological or nonpharmacological interventions had been used before or during that procedure or episode. Examples were given of pharmacological interventions (such as morphine, acetaminophen, topical anesthetics, sucrose), and nonpharmacological interventions (such as positioning, non-nutritive sucking, and psychological interventions such as distraction). Finally, children and/ or caregivers were asked about overall satisfaction with pain management during their current hospitalization, using the same four-point scale.

The chart audit tool included the following demographic characteristics: age, sex, weight, most recent surgical procedure and whether the child was being followed by the Integrated Pain Service. Data from the previous $24 \mathrm{~h}$ related to pain management were extracted from the patient chart including type and dose of analgesic medications administered during the previous $24 \mathrm{~h}$; nonpharmacological interventions documented during painful procedures; documented pain assessment scores; and the pain assessment scales used. The chart audit tool was informed by the Taylor et al (4) study and the larger CIHR Team in Children's Pain study (1) and was deemed to be the most appropriate for the purpose of the present study. 


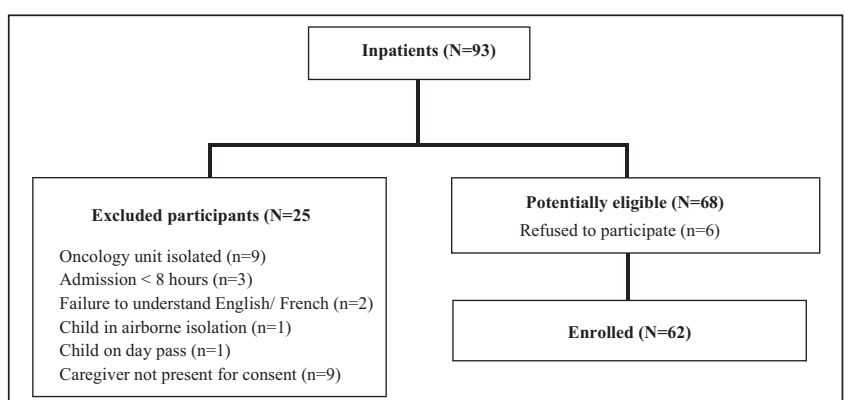

Figure 1) Participant flow chart

Both the interview tool and chart audit tool were piloted for clarity and ease of use for the data collectors. Two PRNs tested the interview tool with three parents and minor modifications were made for clarity. Agreement of the chart audit tool was determined by having two PRNs independently audit the same five charts, before the day of the study. There was high agreement after discussion.

\section{Procedures}

The study protocol was approved by the hospital's research ethics board and support was obtained from the Chief Nursing Executive and the Directors of the inpatient units. The study was publicly promoted throughout the hospital, with advertising and flyers in the week leading up to the study.

Before the day of the study, a $2 \mathrm{~h}$ training session was conducted to introduce the PRNs to the study aims, data collection procedures and tools. Two patient charts were audited to demonstrate the procedure to the PRN data collectors. The two PRNs who had assisted in the development and pretesting the interview tool and the chart audit tools were available throughout the data collection day to answer any questions or concerns.

Data collection took place on November 7, 2011 - the first day of National Pain Awareness Week. Bedside nurses identified eligible children and their caregivers and asked permission for research nurses to approach them to discuss the study. Explanation of the study was given to the child and caregivers, where appropriate. If they agreed, signed informed consent was obtained from caregivers and signed informed assent was obtained from children who were able to give assent. Interviews were offered in French and English. Data were collected by the PRNs as well as the principal investigator (Harrison) and a coinvestigator (Ellis), and included the administration of the interview tool and a chart audit. Interviews were conducted with children who were able to self-report pain intensity and caregivers of infants or children unable to self-report who spoke and understood either English or French. If both the child and caregiver were able to be interviewed together, only one pain score was recorded for these children, which both parties agreed on. Data collection commenced at 0800 so as to not interfere with change of shift activities.

\section{Analysis}

All data were collected on paper and entered into a SPSS database. Descriptive statistics were performed with SPSS (IBM Corporation, USA) (18). Frequencies, ranges, means and their SDs or medians and their interquartile ranges were used to describe the sample depending on the distribution of the data.

\section{Sample}

\section{RESULTS}

There were 93 patients hospitalized on the day of the study. One inpatient unit (oncology) was excluded (nine children) due to an infection outbreak on that unit. Three children who had been hospitalized for $<8 \mathrm{~h}$ were not eligible for inclusion, and an additional 13 children were excluded due to no caregivers being available to provide consent $(n=9)$; failure to understand French or English $(n=2)$; one child was on a day pass and one child was in airborne isolation. This left
TABLE 2

Demographic characteristics

\begin{tabular}{llc}
\hline Child participant characteristic & $\mathbf{n}(\%)$ \\
\hline Age & Newborn - 1 month & $11(18)$ \\
& 31 days - 12 months & $12(19)$ \\
& 13 months - 36 months & $5(8)$ \\
& 37 months - 7 years & $6(10)$ \\
& 8 years - 12 years & $2(3)$ \\
& $\geq 13$ years & $23(37)$ \\
& Not recorded & $3(5)$ \\
Sex & Male & $27(44)$ \\
& Female & $33(53)$ \\
Interview respondent & Not recorded & $2(3)$ \\
& Child & $22(36)$ \\
& Caregiver & $35(57)$ \\
Followed by Integrated & Both & $4(7)$ \\
Pain Service & Not recorded & $1(2)$ \\
& No & $6(10)$ \\
Surgery during this & Not recorded & $54(87)$ \\
hospitalization & Yes & $2(3)$ \\
& No & $17(27)$ \\
& Not recorded & $42(68)$ \\
\hline
\end{tabular}

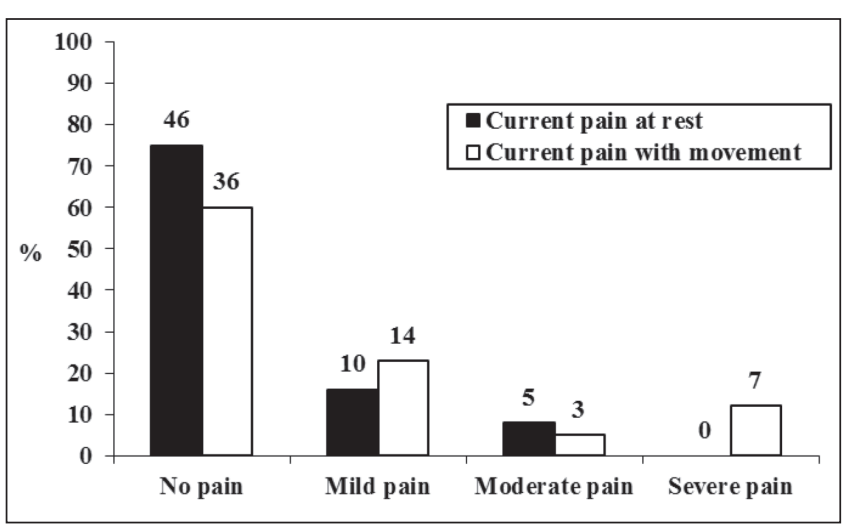

Figure 2) Pain at rest and with movement at time of interview. Number of children (n) represented above bars

68 potentially eligible children. Six children and/or parents (9\%) refused consent to participate in the study. A total of 62 patients from five inpatient units including medicine, surgery, neonatal intensive care and pediatric intensive care were enrolled and participated in the study (Figure 1). The majority of interviews were conducted in English ( $\mathrm{n}=59$ [95\%]), and three interviews were conducted in French.

\section{Demographic characteristics}

The majority of the children in the study were infants $(<12$ months of age) or teenagers ( $\geq 13$ years of age). There were slightly more females $(\mathrm{n}=33$ [55\%]) than males. Six children $(10 \%)$ were followed by the Integrated Pain Service (Table 2).

\section{Child/caregiver interview}

Of the 62 patients interviewed, 51 (82\%) reported some pain during their hospitalization and $62(100 \%)$ experienced a painful procedure. Eleven (18\%) rated the worst pain experienced during their hospitalization as 'mild', 24 (39\%) reported 'moderate' pain while 16 (26\%) had experienced 'severe' pain. At the time of the interview, $10(16 \%)$ children stated that they were experiencing either 'moderate' or 'severe' pain during movement and five (8\%) children reported 'moderate' or 'severe' pain at rest (Figure 2 ). The majority of the children $(n=46[75 \%])$ reported that at the time of the 
TABLE 3

Pain scales used in previous $24 \mathrm{~h}$

\begin{tabular}{lc}
\hline Pain scale* & $\mathbf{n}(\%)$ \\
\hline No scores identified & $28(45)$ \\
Numerical Rating Scale & $19(31)$ \\
Neonatal Infant Pain Scale & $8(13)$ \\
Face, Legs, Activity, Cry, Consolability & $3(5)$ \\
No scales identified (but score given) & $3(5)$ \\
FACES Revised & $2(3)$ \\
Modified COMFORT & $2(3)$ \\
\hline
\end{tabular}

*Some charts used more than one scale for a child

TABLE 4

Analgesics documented in previous $24 \mathrm{~h}$

\begin{tabular}{lc}
\hline Analgesic & $\mathbf{n}(\%)$ \\
\hline Acetaminophen & $26(42)$ \\
Morphine bolus & $7(11)$ \\
Ibuprofen & $6(10)$ \\
Gabapentin & $4(7)$ \\
Hydromorphone bolus & $3(5)$ \\
Ketorolac & $2(3)$ \\
Ametop*/Emlat/Pain Ease ${ }^{\ddagger}$ & $2(3)$ \\
Morphine infusion & $1(2)$ \\
Fentanyl infusion & $1(2)$ \\
\hline
\end{tabular}

${ }^{*}$ Smith \& Nephew, Canada; ${ }^{\dagger}$ AstraZeneca Canada Inc; ${ }^{\ddagger}$ Omniderm Pharma Canada Inc

interview they felt no pain while at rest. All patients, except one child who reported moderate to severe pain at the time of the interview, had received analgesia in the previous $24 \mathrm{~h}(\mathrm{n}=10$ [91\%]). As per the study protocol, for the 11 children who had moderate to severe pain, the researcher or PRN reported this to the child's nurse so action could be taken.

All 62 children and/or their caregivers were asked to identify which pain management strategies the nurses, doctors and other health professionals used during their last needle stick. The most common strategies reported by the children or caregivers were sucrose administration ( $\mathrm{n}=16$ [26\%]); EMLA (AstraZeneca Canada Inc) or Ametop (Smith \& Nephew, Canada) topical anesthetic creams ( $\mathrm{n}=14$ [23\%]); distraction methods ( $\mathrm{n}=14$ [23\%]); the use of a coolant spray such as Pain Ease (GeBauer Company, USA) ( $\mathrm{n}=9$ [15\%]); and eight (13\%) answered that other techniques were used such as a soother and analgesics. Almost one-quarter of the caregivers or children $(n=15$ [24\%]) reported that nothing specific was used during their last needle stick. The most common pain management strategy used for infants up to 12 months of age $(n=23)$ was sucrose $(n=16[70 \%])$; for toddlers 13 to 36 months of age $(n=5)$ was distraction $(n=3[60 \%])$; for school-age children $(n=8)$ four to 12 years of age was topical anesthetic creams $(n=5$ [63\%]); and for teenagers $\geq 13$ years of age $(n=9[39 \%])$ nothing specific had been used during their last needle stick.

All 62 children and/or their caregivers identified their most recent painful procedure or episode during their hospitalization. The most common recent painful procedures or episodes included blood draw $(\mathrm{n}=23 ; 37 \%)$; peripheral intravenous insertion $(\mathrm{n}=7 ; 11 \%)$; abdominal pain $(\mathrm{n}=7 ; 11 \%)$; nasogastric tube insertion $(\mathrm{n}=3 ; 5 \%)$; accessing a porta-cath $(n=2)$; headache $(n=2)$; and physiotherapy $(n=2)$. Twenty-nine $(47 \%)$ children or caregivers reported that analgesics were given before the painful procedure or early in the painful episode. Analgesics were not used in $29(47 \%)$ of the cases and two (3\%) children or their caregivers were unsure if they had received analgesics. The majority of the children and caregivers $(n=32 ; 54 \%)$ reported that nonpharmacological strategies had not been used during or before the painful episode or early in the painful procedure; 19 (32\%) reported that nonpharmacological strategies had been used and six $(10 \%)$ were unsure.

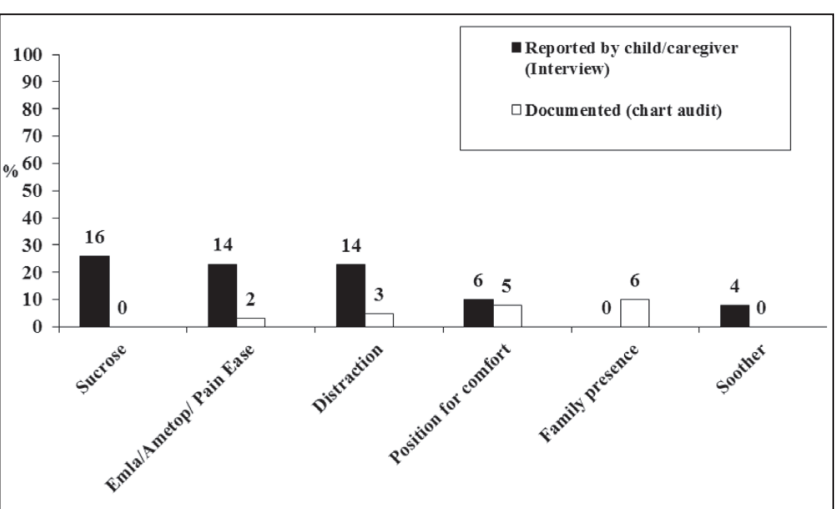

Figure 3) Comparison between reported interventions and documented interventions

The majority of the respondents $(n=44 ; 71 \%)$ were very satisfied with pain management overall; 15 (24\%) were somewhat satisfied, two $(3 \%)$ were somewhat dissatisfied and one (2\%) was very dissatisfied.

\section{Chart audit}

A total of 34 children (55\%) had at least one pain score documented in the previous $24 \mathrm{~h}$ (Table 3 ). In 17 charts, pain scores were obtained within $1 \mathrm{~h}$ of the child being admitted to the unit. Eight (15\%) of the scores were obtained within $2 \mathrm{~h}$ to $12 \mathrm{~h}$ of admission, two (13\%) were obtained $12 \mathrm{~h}$ after admission and 23 (42\%) charts had no pain scores documented. For those patients with pain scores documented, the type of pain scale used varied depending on the unit and the age of the child. The Numerical Rating Scale (19) was used most often ( $n=19 ; 31 \%)$, followed by the Neonatal Infant Pain Scale (20) ( $n=8 ; 13 \%)$; Face, Legs, Activity, Cry, Consolability (21) ( $\mathrm{n}=3 ; 5 \%)$; Modified COMFORT (22) $(n=2 ; 3 \%)$; and the FACES Pain Scale Revised $(23)(n=2 ; 3 \%)$. The median pain score for the Numerical Rating Scale was 5 of 10 and was most commonly used in children aged seven to 17 years (median age 15 years). The median pain score for the Neonatal Infant Pain Scale was 0 of 10 and was most commonly used in infants up to 14 months of age (median age 5.5 months). The median pain score for the Face, Legs, Activity, Cry, Consolability was 0 of 10 and was most commonly used in children 18 to 36 months of age (mean age 23 months). As could be expected, children being followed by the Integrated Pain Service had more frequent pain assessments documented in the previous $24 \mathrm{~h}$. One child's chart had an opioid withdrawal score documented, and two charts had sedation scores documented.

Over one-half of the children $(n=33,53 \%)$ had received analgesia in the previous $24 \mathrm{~h}$. As shown in Table 4, the analgesic agent most frequently administered was acetaminophen. Although 14 (23\%) children or caregivers reported that topical anesthetic creams were used and $16(26 \%)$ caregivers reported sucrose was used before a painful procedure, these strategies were rarely (topical anesthetics) or never (sucrose) documented in the charts (Figure 3).

Nonpharmacological strategies were recorded as being used in the previous $24 \mathrm{~h}$ in only 17 charts. Most commonly documented were positioning for comfort $(n=5 ; 9 \%)$, distraction methods $(n=3 ; 5 \%)$ and other methods $(\mathrm{n}=9 ; 15 \%)$ such as family presence and relaxation methods (Figure 3).

\section{DISCUSSION}

The present study conducted at a tertiary care pediatric hospital during Canada's National Pain Awareness week provided a snapshot of pain prevalence and pain management. Disappointingly, similar to a study conducted in the same setting one decade ago (16), as well as other studies conducted up to two decades ago $(24,25)$, results indicated that significant numbers of infants and children experienced moderate to severe pain during their hospitalization. Other pain prevalence studies conducted more recently are also comparable $(4,26,27)$. Our results 
and those of other recent studies are alarming, highlighting that, despite increasing knowledge of effective pain management strategies for hospitalized infants and children $(11,12)$, an abundance of ageappropriate pain assessment tools aimed at systematic assessment of pain with the aim of improving pain management $(27,28)$ as well as the settings' participation in a nationwide pediatric pain knowledge translation study $(1,29)$, pediatric pain management remains suboptimal.

Some small improvements, however, are evident. Although poorly documented, $26 \%$ of parents of infants reported the use of sucrose, a significant improvement to sucrose use in Canadian NICUs in the 1990s and 2007 (3), and 23\% of parents and children reported use of topical anesthetics for needle-related procedures. This use of topical anesthetics is a small increase of $4 \%$ since an audit of topical anesthetic use for needle-related procedures almost a decade ago in the same setting (30). Only one child in our study who reported moderate to severe pain had not received any analgesia in the previous $24 \mathrm{~h}$, whereas in another Canadian study conducted in 1992, almost onehalf of the children who reported severe pain received no analgesia in the previous $24 \mathrm{~h}(25)$.

However, consistent effective pain management of needle-related procedures remains a problem. In a large nationwide study examining the management of painful procedures in children in Canadian hospitals, blood draws and peripheral intravenous insertions were commonly performed painful procedures in children (1), and another study indicated that capillary and venous blood draws and peripheral intravenous insertions were the three most common painful procedures performed and were considered to be procedures in the 'moderate to severe pain' category (31). Similarly, in our study, almost one-half of children/caregivers identified blood draws or peripheral intravenous insertion as being the most recent painful procedure they encountered, yet less than one-half of the children or caregivers reported that a pharmacological agent had been administered before the painful procedure and less than one-third reported that nonpharmacological interventions had been used. This is despite high-quality evidence demonstrating effective procedural pain management strategies for hospitalized infants and children $(11,12)$.

With respect to procedural pain management strategies, the results of our study indicate a discrepancy between what was reported by patients/caregivers and what was documented in the charts. Although more than one-half of the patients/caregivers reported that sucrose, topical anesthetics or nonpharmacological interventions had been used before their most recent painful procedure or episode, these interventions were documented only $25 \%$ of the time. Similarly, another Canadian study showed that only $15 \%$ of hospitalized children had documented evidence of use of nonpharmacological interventions for painful procedures (31). There is a chance that this result and others reporting minimal use of pain management strategies underestimate the actual use of such strategies. This discrepancy between strategies implemented and documented highlights a key challenge when researchers rely on information documented in patient charts as the only means to evaluate pain care provided to hospitalized children. Clearly, documentation is critical for patient safety, monitoring and evaluation of care. The care/documentation gap needs to be addressed through technology or other means such that nurses can efficiently track the care they provide.

Six children were being followed by the hospital's Integrated Pain Service. This team offers services to children with complex pain problems. All of these children had at least one pain score documented in the previous $24 \mathrm{~h}$ (mean of seven scores documented) and all of them were receiving either analgesics or adjuvant medications. These results are similar to a study that reported that children being followed by an acute pain service were more likely to receive regular analgesia and more likely to have pain assessments documented (4). However, these findings differ from another study that showed that units who accessed specialist pain services administered analgesia less frequently (1). It is possible that pain assessments were being conducted on a more regular basis due to the significant and complex pain being experienced by these patients coupled with the staff's awareness that the children were being followed by the Integrated Pain Service for pain management issues.

Despite hospital policy that states that pain assessments should be performed at least once per shift, almost one-half of the children in the present study had no pain scores documented in their chart in the previous $24 \mathrm{~h}$. Previous studies in Canada and elsewhere have also reported that pain assessments were infrequently documented in children's charts $(4,27,32)$. Children in the surgical unit had pain assessments documented more often than children hospitalized in other units, whereas none of the nine infants in the NICU had pain assessments recorded in the previous $24 \mathrm{~h}$. Numerous studies have reported inconsistent documentation using pain assessment measures available in neonatal units (33-35), despite the existence of $>40$ pain assessment tools suitable for this population $(28,36)$. Much attention by health care professionals and researchers has been devoted to embedding pain assessment into routine pediatric clinical care, yet little overall progress in this respect has been made. A collaborative research effort has been suggested as opposed to further individual implementation studies (28).

Despite the high prevalence of children who either had experienced moderate to severe pain during their hospitalization or reported it during the interview, the majority of the children and/or their caregivers were very satisfied with pain management. These results are similar to a study that reviewed 20 quality improvement studies between 1992 and 2001 and noted that 15 of these studies had reported a high degree of satisfaction with pain management despite many patients experiencing moderate to severe pain during their hospitalization (37). This is consistent with research that suggests there may be factors other than achieving a specific health outcome (such as absence of pain) that contribute to patient satisfaction with health care (38).

Since the present study, a number of strategies have been put in place at the organizational and individual unit level at the study hospital. A new pain management and assessment policy has been introduced, which includes the importance of regular pain assessments and documentation of pharmacological and nonpharmacological interventions. A new medical directive (nurse- and other health professionalsinitiated order) and preprinted orders for the use of sucrose and topical anesthetics have been introduced to facilitate the process of initiating, administering and documenting these interventions. The results of the present study were disseminated widely throughout the hospital at all levels of leadership in the form of presentations, an executive summary and via the PRNs, using individual inpatient unit audit and feedback reports of key results for benchmarking against the mean study results. This unit-specific feedback facilitated an opportunity for the units to identify their key pain assessment and management questions to focus on for future quality improvement activities. This type of individualized audit-feedback can be an effective form of knowledge translation to improve practices (39). However, questions remain about whether these strategies are sufficient to systematically improve pain management, and ensure changes are sustainable.

The ongoing knowledge to practice gaps evident in our study and other pain audits conducted in the past five years $(4,26,27,40)$ highlight the need for effective and sustainable knowledge translation strategies at an organizational level. Such initiatives are already in progress or evolving. The study hospital is one of eight participating pediatric hospital in a Canada-wide CIHR Team in Children's Pain, focused on improving pain management in hospitalized children (29). Results will greatly contribute to our understanding about effective knowledge translation and whether improvements in pain management can be sustained. In the future, the global ChildKind initiative will provide an institutional-wide goal of certification as a hospital committed to uniform best practices in pain management (41). Another avenue of systematic improvement in pain management suggested is to consider pain as an adverse event (42). It will be important to evaluate how effectively these knowledge translation projects and strategies systematically change practice in a sustainable manner. 


\section{Study limitations}

The present study was conducted in a single site with a sample size of only 62 children. A subgroup that was under-represented was children in oncology who were excluded due to closure of the unit. Because children in oncology units undergo large numbers of invasive painful procedures (5) and may experience significant pain as a result of their disease process and treatment, results of the present study may have differed if this population had been included. Furthermore, a very small number of children admitted in the Pediatric Intensive Care Unit were enrolled, making it difficult to draw conclusions regarding this specific population.

Another limitation to the present study was that although children and/or their caregivers were asked whether they had received analgesics before their latest painful procedure or episode or if nonpharmacological strategies had been used, they were not asked whether these methods were effective. Future studies should include this information to determine the effectiveness of pain management methods used. Finally, it is important to note that almost one-half of the children in the present study were preverbal or younger than four years of age; therefore, the majority of the interviewees were caregivers. Although in our study we did not examine congruence between caregiver and child pain scores, some studies have reported close agreement between pain ratings by children, parents and practitioners $(16,43)$, while others have found under-reporting of children's pain severity by parents (44).

\section{Recommendations for further research}

Future research evaluating pain prevalence in a pediatric hospital over a longer period of time would provide more in-depth information about pain management over the course of a child's hospitalization. A follow-up study examining the impact of the individual audit feedback reports would help to determine the effectiveness of this unit-based

\section{REFERENCES}

1. Stevens B, Abbott L, Yamada J, et al. Epidemiology and management of painful procedures in hospitalized children across Canada. CMAJ 2011;183:E403-E10.

2. Carbajal R, Rousset A, Danan C, et al. Epidemiology and treatment of painful procedures in neonates in intensive care units. JAMA 2008;300:60-70.

3. Johnston C, Barrington KJ, Taddio A, Carbajal R, Filion F. Pain in Canadian NICUs: Have we improved over the past 12 years? Clin J Pain 2011;27:225-32.

4. Taylor EM, Boyer K, Campbell FA. Pain in hospitalized children: A prospective cross-sectional survey of pain prevalence, intensity, assessment and management in a Canadian pediatric teaching hospital. Pain Res Manag 2008;13:25-32.

5. Jacob E, Hesselgrave J, Sambuco G, Hockenberry M. Variations in pain, sleep, and activity during hospitalization in children with cancer. J Pediatr Oncol Nurs 2007;24:208-19.

6. Kennedy RM, Luhmann J, Zempsky WT, Kennedy RM, Luhmann J, Zempsky WT. Clinical implications of unmanaged needle-insertion pain and distress in children. Pediatrics 2008;122(Suppl 3):S130-3.

7. Taddio A, Goldbach M, Ipp M, Stevens B, Koren G. Effect of neonatal circumcision on pain responses during vaccination in boys. Lancet 1995;345:291-2.

8. Taddio A, Katz J, Ilersich AL, Koren G. Effect of neonatal circumcision on pain response during subsequent routine vaccination. Lancet 1997;349:599-603.

9. Taddio A, Shah V, Gilbert-MacLeod C, Katz J. Conditioning and hyperalgesia in newborns exposed to repeated heel lances. JAMA 2002;288:857-61.

10. Rennick JE, Morin I, Kim D, Johnston CC, Dougherty G, Platt R. Identifying children at high risk for psychological sequelae after pediatric intensive care unit hospitalization. Pediatr Crit Care Med 2004;5:358-63.

11. Stinson J, Yamada J, Dickson A, Lamba J, Stevens B. Review of systematic reviews on acute procedural pain in children in the hospital setting. Pain Res Manag 2008;13:51-7.

12. Yamada J, Stinson J, Lamba J, Dickson A, McGrath PJ, Stevens B. A review of systematic reviews on pain interventions in hospitalized infants. Pain Res Manag 2008;13:413-20. knowledge translation intervention. Importantly, further research evaluating interventions aimed at sustainable improvements in pain management at organizational and unit-based levels are urgently required.

\section{CONCLUSION}

The results of the 2011 Pain Prevalence study conducted on the first day of National Pain Awareness week in a tertiary referral pediatric hospital in Canada demonstrated that many children continue to experience moderate to severe pain during their hospitalization. This is despite growth over the past decade of high-quality evidence to support various pain management strategies. Working at sustainable improvements in pain management at an organizational and individual unit level should be the focus of future research.

ACKNOWLEDGEMENTS: We thank the infants, children and families at Children's Hospital of Eastern Ontario (CHEO) for their participation in this study, Brenda Martelli and the CHEO Pain Resource Nurses (Karen Batoff, Kowsar Abdulla, Carla Afonso, Lorraine Caven, Sandra Dragic, Sofia Godoy, Tanya Lahti, Kym Newhook, Betty Rowley, Tracey Sigouin, Kristine Tookenay) and Jessica Reszel for their assistance on this study.

FINANCIAL SUPPORT: There was no external financial support for this study.

NAME OF INSTITUTION WHERE WORK ORIGINATED: Children's Hospital of Eastern Ontario (CHEO), Ottawa, Ontario, Canada.

DISCLOSURES: The authors have no conflicts of interest to declare.
13. Harrison D, Stevens B, Bueno M, et al. Efficacy of sweet solutions for analgesia in infants between 1 and 12 months of age: A systematic review. Arch Dis Child 2010;95:406-13.

14. Pillai Riddell RR, Racine NM, Turcotte K, et al. Nonpharmacological management of infant and young child procedural pain. Cochrane Database Syst Rev 2011;(10):CD006275.

15. Stevens B, Yamada J, Lee GY, Ohlsson A. Sucrose for analgesia in newborn infants undergoing painful procedures. Cochrane Database Syst Rev 2013;(1):CD001069.

16. Ellis JA, O'Connor BV, Cappelli M, et al. Pain in hospitalized pediatric patients: How are we doing? Clin J Pain 2002;18:262-9.

17. Goodenough B, Piira T, von Baeyer CL, et al. Comparing six selfreport measures of pain intensity in children. The Suffering Child 2005;8:1-25.

18. IBM Corp. IBM SPSS Statistics for Windows, version 20.0. Armonk: IBM Corp; 2011.

19. von Baeyer CL, Spagrud LJ, McCormick JC, et al. Three new datasets supporting use of the Numerical Rating Scale (NRS-11) for children's self-reports of pain intensity. Pain 2009;143:223-7.

20. Lawrence J, Alcock D, McGrath P, et al. The development of a tool to assess neonatal pain. Neonatal Net 1993;12:59-66.

21. Merkel SI, Voepel-Lewis T, Shayevitz JR, Malviya S. The FLACC: A behavioral scale for scoring postoperative pain in young children. Pediatric Nursing 1997;23:293-7.

22. Carnevale FA, Razack S. An item analysis of the COMFORT scale in a pediatric intensive care unit. Pediatr Crit Care Med 2002;3:177-80.

23. Hicks CL, von Baeyer CL, Spafford PA, van Korlaar I, Goodenough B. The Faces Pain Scale-Revised: Toward a common metric in pediatric pain measurement. Pain 2001;93:173-83.

24. Cummings EA, Reid GJ, Finley GA, McGrath PJ, Ritchie JA. Prevalence and source of pain in pediatric inpatients. Pain 1996;68:25-31.

25. Johnston CC, Abbott FV, Gray-Donald K, Jeans ME. A survey of pain in hospitalized patients aged 4-14 years. Clin J Pain 1992;8:154-63.

26. Groenewald CB, Rabbitts JA, Schroeder DR, Harrison TE. Prevalence of moderate-severe pain in hospitalized children. Paediatr Anaesth 2012;22:661-8. 
27. Stevens B, Harrison D, Rashotte J, et al. Pain assessment and intensity in hospitalized children in Canada. J Pain 2012;13:857-65.

28. Harrison D. Implementation matters: Pain assessment: Not yet normalized practice. Special Interest Group on Pain in Childhood, International Association for the Study of Pain; Newsletter 2009; August:4-5.

29. Stevens B. The Canadian Institutes of Health Research (CIHR) Team in Children's Pain. CTP-79854. 2006-2012.

30. Ellis J, Sharp D, Newhook K, Cohen J. Selling comfort: A survey of interventions for needle procedures in a pediatric hospital. Pain Manage Nurs 2004;5:144-52.

31. Zhu LM, Stinson J, Palozzi L, et al. Improvements in pain outcomes in a Canadian pediatric teaching hospital following implementation of a multifaceted knowledge translation initiative. Pain Res Manag 2012;17:173-9.

32. Twycross A. Children's nurses' post-operative pain management practices: An observational study. Int J Nurs Stud 2007;44:869-81.

33. Harrison D, Loughnan P, Johnston L. Pain assessment and procedural pain management practices in neonatal units in australia. J Paediatr Child Health 2006;42:6-9.

34. Brunt $\mathrm{A}$. The use and documentation of oral sucrose on a neonatal intensive care unit. Anaesth Intens Care 2012;40:533.

35. Foster J, Spence K, Henderson-Smart D, Harrison D, Gray P, Bidewell J. Procedural pain in neonates in Australian hospitals: A survey update of practices. J Paediatr Child Health 2012;49:E35-E9.
36. Duhn LJ, Medves JM. A systematic integrative review of infant pain assessment tools. Adv Neonatal Care 2004;4:126-40.

37. Gordon DB, Pellino TA, Miaskowski C, et al. A 10-year review of quality improvement monitoring in pain management: Recommendations for standardized outcome measures. Pain Manage Nurs 2002;3:116-30.

38. Worthington C. Patient satisfaction with health care: Theoretical developments and implications for evaluation practice. Can J Program Eval 2005;20:41-63.

39. Ivers N, Jamtvedt G, Flottorp S, et al. Audit and feedback: Effects on professional practice and healthcare outcomes. Cochrane Database Syst Rev 2012;(6):CD000259.

40. Schechter N. From the ouchless place to comfort central: The evolution of a concept. Pediatrics 2008;122:S154-60.

41. Schechter N, Finley G, Bright N, Laycock M, Forgeron P. Childkind: A global initiative to reduce pain in children. Pediatric Pain Letter 2010;12:26-30.

42. Chorney J, McGrath P, Finley G. Pain as the neglected adverse event. CMAJ 2010;182:732.

43. Chambers C, Reid G, Craig K, McGrath P, Finley G. Agreement between child and parent reports of pain. Clin J Pain 1998;14:336-42.

44. Singer AJ, Gulla J, Thode HC Jr. Parents and practitioners are poor judges of young children's pain severity. Acad Emerg Med 2002;9:609-12. 


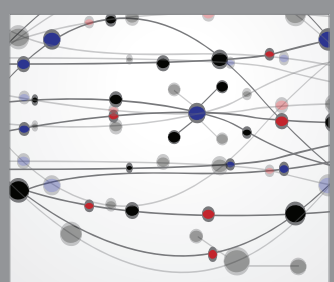

The Scientific World Journal
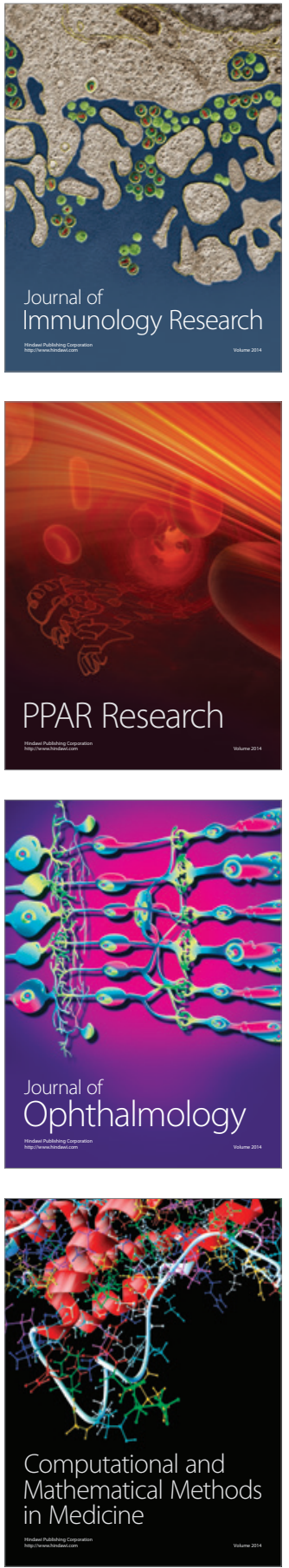

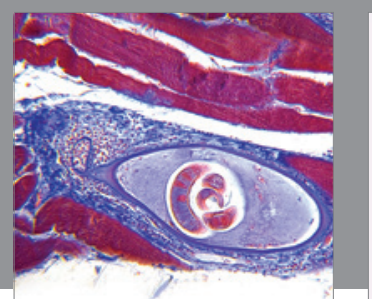

Gastroenterology Research and Practice

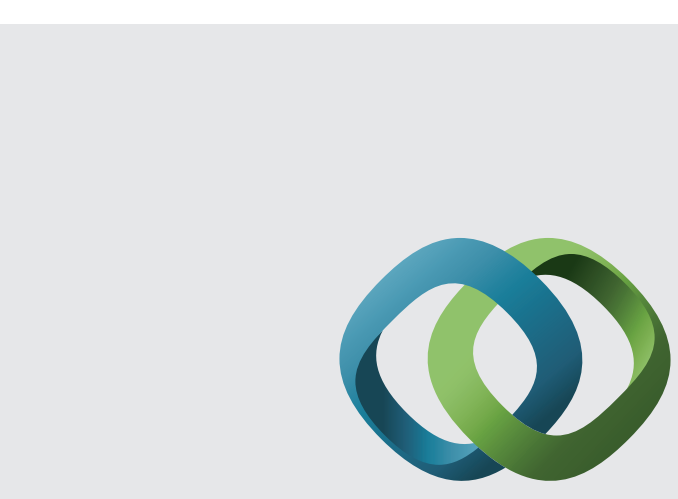

\section{Hindawi}

Submit your manuscripts at

http://www.hindawi.com
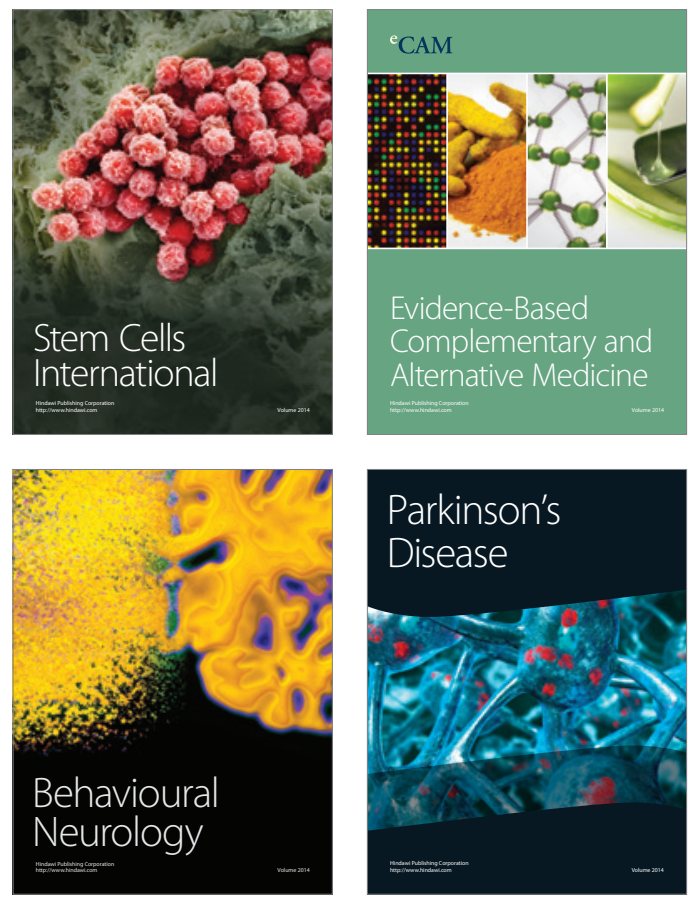
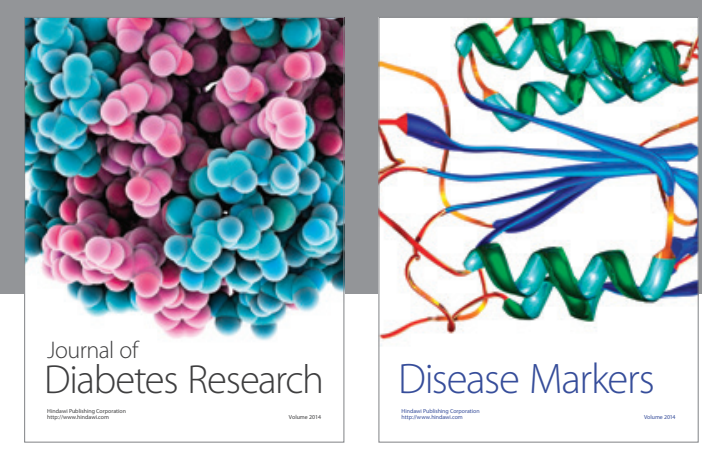

Disease Markers
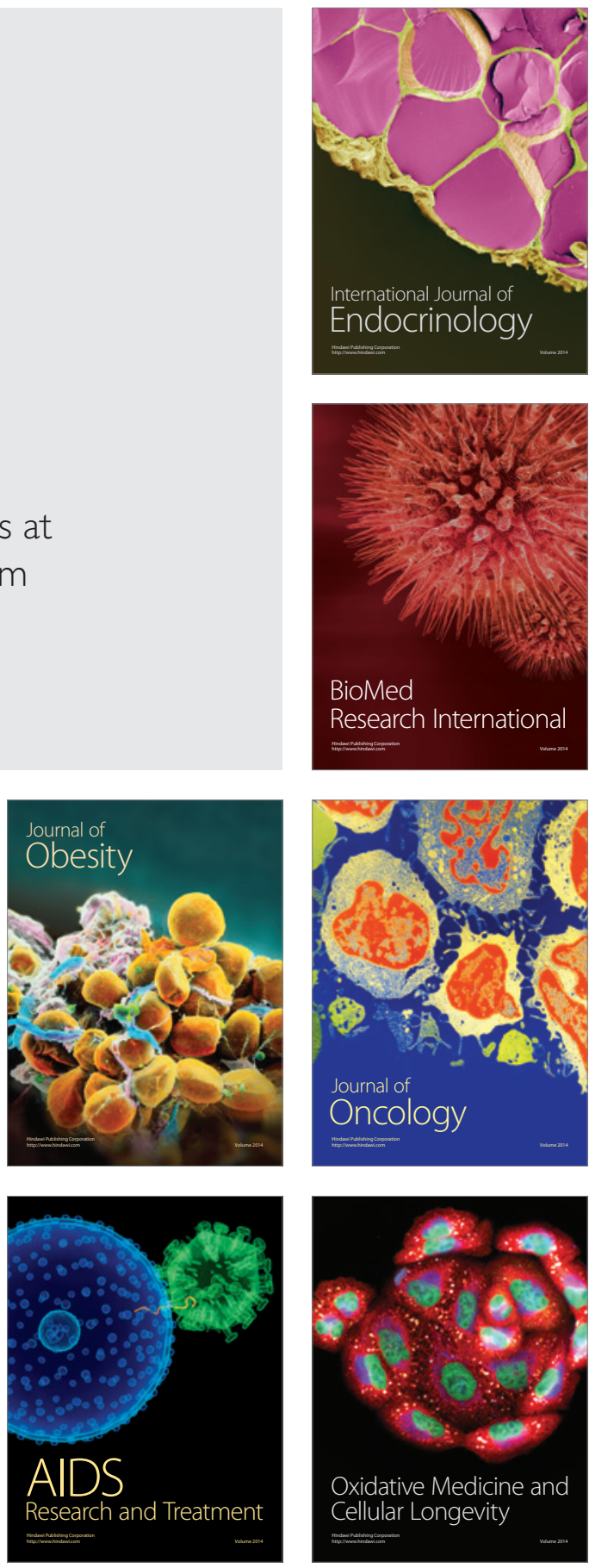